\title{
Is the global conservation status assessment of a threatened taxon a utopia?
}

\author{
Gregor Kozlowski
}

Received: 26 June 2007 / Accepted: 23 October 2007 / Published online: 3 November 2007 (C) Springer Science+Business Media B.V. 2007

\begin{abstract}
The signatory countries of the Convention on Biological Diversity agreed to significantly reduce the rate of biodiversity loss by 2010 . How will we know, however, if we have achieved this goal? Eight groups of hindrances in evaluating the global conservation status of threatened taxon are identified: (1) the extreme heterogeneity and (2) restricted availability of relevant data; (3) the uncertainty in species number and taxonomic division of the given taxon (Linnean shortfall); (4) the fragmentary distribution knowledge (Wallacean shortfall); (5) the incomplete or incorrect red-listing across the whole distribution area; (6) the lack of homogeneous and exhaustive population trend data; (7) the threat knowledge shortfall; (8) the incomplete general biological knowledge on a given taxon. The Linnean and Wallacean shortfalls lay the foundation of all other hindrances. So long as this dramatic shortfall situation does not change, the adequate assessment of the global status for overwhelming majority of extant taxa will remain a utopia.
\end{abstract}

Keywords Linnean shortfall $\cdot$ Wallacean shortfall $\cdot$ Red-listing $\cdot$ Conservation priority setting · Data defficiency

During the last centuries the dimension of anthropogenic alteration of natural habitats and the extinction crisis has attained levels never seen during human history (Brown and Lomolino 1998; Jenkins 2003). In the very near future this tendency will not relent since the acquisition of natural resources for human needs will expose the environment and all living organisms to even more drastic changes (Foley et al. 2005).

The signatory countries of the Convention on Biological Diversity (CBD) agreed to significantly reduce the rate of biodiversity loss by 2010 (Brooks and Kennedy 2004). How will we know, however, if we have achieved this goal? Although there are growing efforts in order to improve the methods of conservation status assessment, such newly developed "barometers of biodiversity" can only be applied for an infinitely small fraction of the global biodiversity (e.g., for well-studied vertebrate groups such as birds) (Butchart et al.

G. Kozlowski ( $\square)$

Department of Biology, University of Fribourg, Ch. du Musée 10, CH-1700 Fribourg, Switzerland e-mail: gregor.kozlowski@unifr.ch 


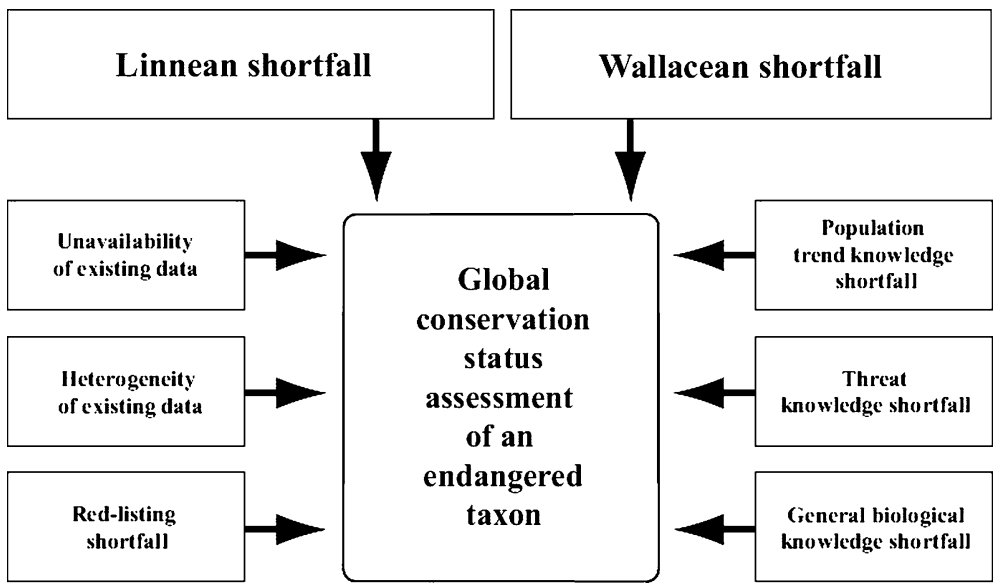

Fig. 1 Hindrances to overcome: scientists and conservationists trying to assess the global conservation status of any chosen endangered taxon are faced with numerous shortfalls and obstacles

2004; Rodrigues 2006). Therefore, although well intended, CBD and similar political agreements are nothing more than a desire which confronts the scientists and conservationists with almost insoluble problems.

Faced with limited time and funding conservation actions and conservation assessments have to rely on priority settings, which will be one of the most challenging issues for conservation biology during the next decades (Master 1991; Roberge and Angelstam 2004). The problem seems simple: we have to start our conservation efforts with species or taxonomic groups which are threatened worldwide. Aware of this problem, many scientific and governmental organizations are planning to create in the next years new priority lists of endangered species taking into consideration their global conservation status. How realistic is, however, such global assessment of the conservation status of any taxon-candidate for such priority list?

The hindrances in such global conservation status assessment can be divided into eight categories (Fig. 1). One of the first barriers will be the low availability of the existing data as well as its extreme heterogeneity (if any data exist at all). For the majority of biota the information published in peer-reviewed journals and books is extremely sparse. Indeed, most of the valuable data are hidden in local journals, in local data-bases, in unpublished theses, reports, action plans, field surveys, and all that written in many languages. The numerous online compendiums of described species launched during last few years are either in a developmental stage (e.g., Encyclopedia of Life assisted by Edward O. Wilson: http://www.eol.org) or still extremely incomplete (Catalogue of Life: http://www.catalogueoflife.org).

Two recent papers of Whittaker et al. (2005) and Bini et al. (2006) demonstrated, however, that the so-called Linnean and Wallacean shortfalls are laying the foundation of all other hindrances in global conservation status assessment. The Linnean shortfall refers to our extremely limited knowledge of the overall biodiversity on our planet (Brown and Lomolino 1998). It is generally accepted that the number of undiscovered organisms surpasses considerably the number of described taxa. Very well-known and often repeated in the public media, is the problem of so-called Centilenan extinctions (Wilson 1992) when undiscovered species go extinct before they are known to science (Brown and Lomolino 1998). However, even in very well studied regions and in relatively well known groups of 
organisms the Linnean shortfall is still an important and topical deficiency (Marris 2007). Furthermore, the general tendency at universities is rather to weaken (or even to stop) the support of taxonomic studies. This recent negligence of taxonomy is inexplicable and stays in direct contradiction to the international biodiversity agreements mentioned above.

The Wallacean shortfall, as it was named by Lomolino and Heaney (2004), refers to our inadequate knowledge of global, regional and even local distribution of a given taxon. It was named after A. R. Wallace who was one of the founders of biogeography. The distribution data deficit is not only typical of poorly studied organisms (e.g., nematodes) but also, for example, of mammals or vascular plants in Europe (Whittaker et al. 2005). Given the massive improvements in computer power, the Wallacean shortfall is the most embarrassing for scientific community. The core of the problem lies in the insufficient support for both field surveys and collection inventories. In many countries, such extremely laborious surveys are perceived by national science foundations as applied and thus not fitting well into modern university strategy. On the other side, for governmental conservation agencies and private foundations, inventories and mapping are seen as part of fundamental science and thus should be covered by universities. This vicious circle needs immediate scientific and political solution.

Until recently, World Conservation Union (IUCN) Red Lists were the most popular conservational tools for designating the priorities in conservation efforts (Gärdenfors et al. 2001). The traditional red lists, however, operate almost exclusively at national level. Additionally, the criteria developed by IUCN are not always applicable for a specific area (e.g., a very small country) or for taxa with a complex biology (e.g., migratory birds) (Gärdenfors et al. 2001; Keller et al. 2005). Red-listing shortfall, however, refers not only to these conceptual problems but much more to the very prosaic one: there are still many countries and even whole continents, which for the majority of taxa do not have any listing of threatened species at all.

The knowledge on population trends is still another important element in the evaluation of the real extinction risk. In order to know whether a given taxon is regressing or not, we need as exact as possible indications on the number of its populations, and this for several temporal data points. Further, it is important to know whether the given taxon is endangered by a major factor such as global warming or by a relatively minor or strongly localized threat such as overhunting or overcollecting by the local human population. Since the spectrum of such anthropogenic threats to biodiversity is very broad, the threat knowledge shortfall could significantly hinder the global conservation status assessment. Finally, the inadequate general biological knowledge other than distribution and taxonomy (e.g., reproduction biology, demographic processes, genetic diversity, dispersal mechanisms, etc.) has an enormous influence on the global conservation status of any taxon under consideration. Such detailed biological knowledge is available, once again, for only an extremely small portion of all taxonomic groups. It is evident that all hindrances described above are strongly interdependent (see Fig. 1). The population trend shortfall, for example, is on one hand responsible for the red-listing shortfall; on the other hand it results from the Wallacean or Linnean shortfall.

So long as this dramatic knowledge deficiency does not change, the adequate assessment of the global status for the overwhelming majority of extant taxa will remain a utopia. There are some partial solutions of this problem. Scientists could, for example, learn more of how to deal with the uncertainty and reliability of the available data (Todd and Burgman 1998; Burgman et al. 1999). We could also undertake more efforts in order to improve the information exchange among different conservation actors (scientists, administration units, politicians, local conservation agents, etc.) (Rodrigues 2006). The danger is that by doing 
so most of the scientists and governments will remain muddled in debates about methods and concepts, whereas the basis of the problem will remain unchanged (Green 2005). Thus, real change in future conservation efforts will be only possible if governments incorporate the biodiversity conservation objectives within their substantially funded conservation programmes at a financial level comparable with the economic development programmes (McLean et al. 1999).

\section{References}

Bini LM, Diniz-Filho JAF, Ranger TFLVB, Bastos RP, Plaza Pinto M (2006) Challenging Wallacean and Linnean shortfalls: knowledge gradients and conservation planning in a biodiversity hotspot. Divers Distrib 12:475-482

Brooks T, Kennedy E (2004) Biodiversity barometers. Nature 431:1046-1047

Brown JH, Lomolino MV (1998) Biogeography. Sinauer Press, Sunderland

Burgman MA, Keith AD, Walshe TV (1999) Uncertainty in comparative risk analysis for threatened Australian plant species. Risk Anal 19:585-598

Butchart SHM, Stattersfield AJ, Bennun SM, Shutes SM, Akçakaya HR, Baillie JEM, Stuart SN, HiltonTaylor C, Mace GM (2004) Measuring global trends in the status of biodiversity: red list indices for birds. PLoS Biol 2:2294-2304

Foley JA, DeFries R, Asner GP, Barford C, Bonan G, Carpenter SR, Chapin FS, Coe MT, Daily GC, Gibbs HK, Helkowski JH, Holloway T, Howard EA, Kucharik CJ, Monfreda C, Patz JA, Prentice IC, Ramankutty N, Snyder PK (2005) Global consequences of land use. Science 309:570-573

Gärdenfors U, Hilton-Taylor C, Mace GM, Rodriguez JP (2001) The application of IUCN red list criteria at regional levels. Conserv Biol 15:1206-1212

Green DM (2005) Designatable units for status assessment of endangered species. Conserv Biol 19:1813-1820

Jenkins M (2003) Prospects for biodiversity. Science 302:1175-1177

Keller V, Zbinden N, Schmid H, Volet B (2005) A case study in applying the IUCN regional guidelines for national Red Lists and justifications for their modification. Conserv Biol 19:1827-1834

Lomolino MV, Heaney LR (eds) (2004) Frontiers of biogeography: new directions in the geography of nature. Sinauer Associates, Sunderland

Marris E (2007) The species and the specious. Nature 446:250-253

Master LL (1991) Assessing threats and seting priorities for conservation. Conserv Biol 5:559-563

McLean IFG, Wight AD, Williams G (1999) The role of legislation in conserving Europe's threatened species. Conserv Biol 13:966-969

Roberge J-M, Angelstam P (2004) Usefulness of the umbrella species concept as a conservation tool. Conserv Biol 18:76-85

Rodrigues ASL (2006) Are global conservation efforts successful? Science 313:1051-1052

Todd CR, Burgman MA (1998) Assessment of threat and conservation priorities under realistic levels of uncertainty and reliability. Conserv Biol 12:966-974

Whittaker RJ, Araujo MB, Jepson P, Ladle RJ, Watson JEM, Willis KJ (2005) Conservation biogeography: assessment and project. Divers Distrib 11:3-23

Wilson EO (1992) The diversity of life. Belknap Press, Cambridge 